\title{
DEMAND FOR PRIVATE HEALTH INSURANCE: IS THERE A QUALITY GAP?
}

\author{
Joan Costa ${ }^{\mathrm{a}, \mathrm{c}}$ and Jaume García ${ }^{\mathrm{b}}$
}

a. Departament de Teoria Econòmica, Universitat de Barcelona, Barcelona, Spain.

b. Departament d'Economia i Empresa, Universitat Pompeu Fabra, Barcelona, Spain.

c. LSE Health and Social Care, London School of Economics ,London, UK.

\section{Acknowledgements}

We gratefully acknowledge useful suggestions from Timothy Besley, Elias Mossialos and Dereck King to former versions of this paper. Joan Costa acknowledges funds from the grant CICYT-SEC99-0698 and Jaume García from the grant DGESIC PB98-1058-C03-01. 


\section{Summary}

Quality of care is qualified as a main determinant of the demand for voluntary private health insurance (PHI) in National Health Systems (NHS). This paper provides new evidence on the influence of the quality gap between public and private health insurance and other demand determinants in the demand for PHI in Catalonia. The demand for PHI is modelled as a demand for health care quality. Unlike previous studies, the database employed allows for the development of a link between the theoretical and the empirical model dealing with unobserved heterogeneity and endogeneity issues. Results suggest that a rise in PHI quality enhances an equivalent influence in the demand for PHI as an equal reduction of NHS quality. Income and price elasticity estimates are consistent with the observed feature that PHI appears to be a luxury good and individuals tend to be relatively insensible to tax relief's and monetary co-payments in insurance contracts.

Keywords: private health insurance, health care quality, insurance premium.

JEL: I1; G1 


\section{Introduction}

The coexistence of public and private health insurance is currently a matter of extensive discussion among economists and policy makers. Although the National Health System (NHS) provides universal access to health care, a significant share of the population choose the alternative of private health care when exists. An explanation for the expansion of the private health insurance market may lie on public concerns regarding the quality gap between the NHS and private health care [1]. Accordingly, in order to fund private health care, some individuals purchase private health insurance (PHI) policies to overcome NHS quality constraints and access barriers - i.e waiting time and waiting lists for elective surgery-, by purchasing private health insurance plans $[\mathbf{1 , 2 , 3 ]}$.

As far as the NHS typically provides uniform health care, it is conceivable that difficulties will appear in meeting the expectations of heterogeneous groups' demanding "personalised" health care [4], greater choice and promptness of delivery. Furthermore, access barriers may produce public dissatisfaction and reduce perceived quality of potential and current NHS users. Access barriers in public health systems refer to waiting lists and waiting time [5], but also bureaucratisation and the need of GP's referrals to visit specialist doctors. The expected effect of small quality and access barriers is the reduction of the value of some set of the NHS health care competing with the private sector [6] and consequently the expansion of private alternatives.

Strong equity and efficiency arguments appear behind the role of private health insurance (PHI). The expansion of private alternatives may also result in some specific circumstances in a reduction of the public pressures to the health system [7]. It has been argued that the development of the market for private health enhances beneficial consequences on the redistributional role of the NHS as pointed out in Besley and Coate (1991) [8]. The argument establishes that since the rich tend to opt-out to the private insurance alternatives, those who benefit the most from the NHS are the relatively poor. Hence, public provision of health care under NHS systems may be an efficient redistributive mechanism because the delivery of care is still based on a "needs criteria" whereas contributions rely on income. Nevertheless, those who opt out from the NHS may not be willing to improve the NHS quality 
of care, and hence, the existent gap between the public and private health insurance may tend to remain.

This paper provides new evidence on the determinants of the demand for voluntary private health insurance. We focus on two issues that have received less attention in the literature. First, the combined influence of both the NHS and PHI perceived health care quality. We shed some light on the effect of an improvement (reduction) of the publicly (privately) funded health care quality in the demand for PHI. Second, to the extent that our database contains sufficient records on the premium consumers' pay for PHI and income, price and also income elasticities are estimated and reported. Third, the link between the theoretical and the empirical model is explicitly described dealing with unobserved heterogeneity and endogenenity issues. Forth, empirical results enable a discussion of the expected effects that an improvement of NHS and private health care quality is likely to enhance in the development of the PHI market.

Results from this study are specially relevant in the light of the theory of public provision of private goods $[\mathbf{4 , 9 , 1 0 ]}$. Since PHI can be a partial substitute of the NHS, public concerns on the health care quality gap between the NHS and private health care may foster the purchase of PHI policies. Quality of care is claimed to be dependent on the funding status of the NHS. Accordingly, the growth of PHI is partially attributed to pressures limiting public health spending that result in a lower quality of publicly funded health care [11,12]. This feature has motivated a stream of research examining the interactions between the public and private sector.

A first approach has focused on investigating the existence of captivity in the demand for PHI. Evidence of this phenomenon would suggest that some people might never purchase PHI even when its affordable, as far as they are catalogued as captive to the NHS. This may be reinterpreted as an unwillingness to pay for a hypothetically higher health care quality if provided by the private sector. Propper (1993) [13] investigated the role of captive preferences to the British NHS as constraining the specification of the demand for health insurance. Using a slightly similar approach it has been shown that some share of the population may be captive to the private health sector when there is a large tradition of purchasing PHI and a long-term relationship with private providers [14]. 
A second approach focuses on two aspects: the role of waiting lists as a rationing instrument and political beliefs. Besley et al (1996) [1] found that waiting lists and political beliefs were associated with a higher demand for PHI. In two further studies Besley et al provide additional evidence for Britain. Besley et al (1998) [3] showed that higher levels of PHI may affect the length of regional waiting lists. Besley et al (1999) [2] found a significant effect of long term waiting lists on the decision to purchase PHI. Furthermore, they found that supporters of the Conservative party were more likely to purchase PHI. Long -term waiting lists may be seen as an indirect measure of quality of care measure that provides an incentive to look for alternatives to the NHS. Political beliefs may constrain perceptions on NHS and PHI quality of care as determine individual attitudes towards both the public and private sector. An alternative approach relies on estimating the effect on individual utility by using satisfaction measures. Calnan et al (1993) [15] identified satisfaction with the NHS as influencing the purchase of PHI. NHS satisfaction may be conceived as a measure of individual utility. If the NHS provides less utility to consumer's respect to PHI alternatives, individuals may be more inclined to purchase PHI.

Previous Spanish studies based on individual data can be classified according to the database and the empirical methodology employed. A first source of studies use the Spanish household survey to estimate the participation and the health care consumption equations without correcting for the health and health care utilisation effects. Findings show the influence of socio-economic variables such as income, social class and occupation [16, 17]. A second source of studies employ the Spanish and Catalan Health Surveys. This has enabled the use of limited dependent variable models to study of the existence of adverse selection and moral hazard effects [18], the role of the nature of illness and the existence of captive preferences [19], the influence of time spend in waiting time [20]. A different approach was employed in Vera-Hernández (1999) to study the selection process under duplicate coverage [21]. Count data models were used to estimate health care utilisation using generalized method of moments (GMM) and a reduced form of the PHI demand to correct for endogeneity. At present neither household nor health surveys contain direct information on 
insurance premia and health care quality. Here we exploit an alternative database that contains individual data referred to Catalonia and we use a two-stage procedure .

The structure of the paper is as the follows. In section 2 we summarise the main features characterising the Catalan Health System and the database employed. Section 3 reports a simple theoretical framework and discusses the expected theoretical results. Section 4 provides prior empirical evidence and underlines the empirical model. In section 5 we explore the estimated results and finally section 6 concludes with a discussion section. 


\section{Health insurance in Catalonia and the data}

\subsection{The Catalan health system}

In Spain, as in most OECD countries the State is major funder of health care. Since 1986, the Spanish NHS offers universal coverage and free of charge health care with the exception of pharmaceuticals and dental care. The Spanish health system is regionally decentralised [22]. Catalonia is legally one of the seven Spanish autonomous regions responsible for health care. Unlike other regions, more than half of Catalan health expenditure is private (non-profit). Furthermore, the Catalan Health System is a contractual rather than an integrated based system. Notice that, in this circumstance, the distinction between public and private health sectors essentially refers to the funding rather than the delivery of health care. This may have some further implications in the way people perceive quality of care.

PHI has played a historical role in financing private health care in Catalonia and still does. From an individual perspective it may fill the health care gap resulting from the small flexibility of the NHS to attend individual demands for quality of care. In Spain public servants can choose an alternative insurance to the NHS coverage, however in Catalonia less than a 5\% of the population are currently in this option. PHI schemes show some similarities with the Health Maintenance Organisation's (HMO). Typically, benefits are received in kind rather than reimbursed to the patient. As shown in table 1, 22-23\% of the Catalan population purchases some source of private insurance, a percentage which is far more than in the rest of Spain (16\%). Due explained characteristics, the study of the influence of the quality gap between private and public insurance in Catalonia seems to be especially interesting as are health care related variables the ones that appear as explanatory of the PHI demand [21].

PHI in Spain provides coverage against the event of private medical treatment. It is mainly individually rather than corporately purchased. Even though there a large set of motives explaining PHI demand, well known reasons are the avoidance of waiting lists [1,2] and waiting time [7] and the provision of individualised medical care [2]. Other motives are health care choice improvement and health information [11]. Regarding the source of health care offered, PHI essentially supplies elective care rather than urgent procedures. 


\section{Insert table 1 here}

\subsection{The nature of the data}

At present no public survey contains direct information on the quality assessment of public and private health care. Therefore, a specific survey was conducted to obtain information on insurance premia and individual perceptions of quality. Data was taken from a specifically designed computer based survey. This survey was approached by a specialised firm on market and opinion research between June and July 1999. Although the sample is relatively small $(\mathrm{N}=400)$, it is representative of provinces and relies on households rather than individuals. Respondents were identified and asked questions related to holding private health insurance, quality aspects of health insurance and socio-economic characteristics. The two most relevant records that base our study are perceived quality assessment of both the NHS and the PHI and the declared insurance premium each head of the household pays for itself and their relatives. The questionnaire contains records on health status and disability, health care utilisation as well as attitudes towards private health insurance. The quality of this information appears to be far enough for our purposes as no missing data problems were encountered ${ }^{1}$.

\footnotetext{
${ }^{1}$ There are no large differences with other comparable estimates obtained from the Catalan health survey and other published statistical data. For instance, those having a PHI were a $22.7 \%$ according to the Catalan Health Survey 1994 estimates and in our sample they represent a 23\% in 1999.
} 


\section{The theoretical framework}

The decision to purchase a PHI policy may be seen as of a discrete nature. As far as PHI provides elective health care at a higher quality than the NHS, it's natural to assume that individuals would not simultaneously consume the same health care at the NHS and the private sector [11]. Individuals demand a good in the private sector that is supplied at a hypothetically lower quality by the NHS sector but at no monetary cost. Even though some authors argue there is an intangible co-payment in the NHS health care utilisation [21] here we integrate access barriers within the concept of perceived health care quality. Since preferences for health care quality may differ across individuals, not all individuals that can afford PHI will actually purchase it. This latter evidence was shown by Johanesson et al (1998) [23] employing an insurance approach to estimate the decision to switch into the private sector to reduce waiting lists. If this is the case, using either the length of waiting lists or any other indirect quality variable as a quality of care measure may incompletely capture preferences for health care quality. In this study, the reference variable to base our approach is a direct measure of perceived health care quality.

Health care quality is catalogued as a measurable variable ranging from $Q \in\left[Q_{\max }, 1\right]$. Obviously, the value of $Q_{\max }$ depends on the scale employed. As noticed before it may capture the broad dimensionality of health care quality. NHS quality $\left(Q^{0}\right)$ its assumed to be dependent on some noticeable characteristics that steams from the "uniformity" of health care, namely large waiting lists and waiting times, less flexibility to cope with individual specific needs and less attention to "non-clinical" health care outcomes. Alternatively, PHI provides a more "individualised" care, waiting lists are infrequent and in general, benefits associated with the delivery of care tend to be higher. There is no need to assume that clinical quality differs between the public and private sector. As privately insured individuals have duplicate coverage, they enjoy the same health care quality as the rest, but as they can avoid the uniformity of NHS health care and access barriers in competing health care barriers, they enjoy of a higher health care quality. If $Q^{1}$ represents the quality of private health care, it's natural to state that $Q^{1} \geq Q^{0}$. 
Quality of care is assumed to be an argument of the individual utility function altering the valuation of health care. Health care $(M)$ may be seen as a composite commodity of a basic health care $\left(M_{0}\right)$ that is assumed not to differ between the public and the private alternative, a quality adjustment term $\left(Q^{i}\right)$ and an private health care costs (p) as (1) shows where $i=1,0$ refers to the private and public alternative respectively:

$$
M=M\left(M_{0}, Q^{i}, p\right)
$$

Under these circumstances, if there is a private alternative to the NHS the main decision variable is health care quality and expected medical costs. Lets assume for simplicity that PHI companies charge an actuarial fair insurance premium $(\pi)$ such that $\pi=p \eta$ where $p$ refers to health care costs and $\eta$ refers to the probability of illness. This means that if $\eta<1$ then always $\pi<p$. That is, it is always preferable to consume private health care under an insurance scheme rather than out of pocket if the probability of illness is less than one.

Individuals show two alternative options: not purchasing PHI which means under these assumptions consuming health care at a fixed quality $Q^{0}$ not paying additional charges $\left(Q^{o}, 0\right)$, or purchasing PHI, which implies a higher quality of care but simultaneously a reduction in net income by the amount of the insurance premium $\left(Q^{1}, \pi\right)$.

As a given assumption, individuals are assumed to be risk averse and expected utility maximizers. Therefore, utility functions are concave and increasing in its arguments. Individual utility determinants can be summarised in two main arguments: quality of care and income. Thus, the decision to purchase PHI will be determined by the utility gain derived from a rise in health care quality and the disutility that arises from a reduction in income as a result of paying an insurance premium. Therefore, the decision to purchase PHI will result if $U\left(Q^{0}, y, \eta\right)<U\left(Q^{1}, y-p, \eta\right)$.

This result may be generalised within an expected utility framework. Individuals are assumed to behave as expected utility maximizers. That is, they max 
$V\left(Q_{0}, Q_{1}, \pi(\eta), y\right)=\max \left[V\left(Q_{1}, y-\pi\right), V\left(Q_{0}, y\right)\right]$. If an individual purchases a PHI its expected utility $\mathrm{V}(\cdot)$ is :

$$
V_{l}\left(Q^{l}, y, p, \eta\right)=\eta U\left(Q^{l}, y-p \eta Q^{l}\right)+(1-\eta) U\left(y-p \eta Q^{l}\right)
$$

and if individual decides not to purchase PHI, then the expected utility is :

$$
V_{0}\left(Q^{0} y, p, \eta\right)=\eta U\left(Q^{0}, y\right)+(1-\eta) U(y)
$$

Therefore, the purchase of PHI implies that the expected utility gain $(V G)$ form the purchasing $\mathrm{PHI}$ is positive, i.e

$$
V G\left(Q^{l}, Q^{0}, \pi, y, \eta\right) \geq 0 \text { if } V_{1}\left(Q^{l}, y, \pi, \eta\right) \geq V_{0}\left(Q^{o} y, \pi, \eta\right)
$$

Equation 4 illustrates the key variables influencing the demand for PHI. Relevant variables are: insurance premium $(\pi)$, income $(y)$, quality perceptions of both private heath care $\left(Q^{l}\right)$ and NHS health care $\left(Q^{0}\right)$, and the probability of illness $(\eta)$. Finally, and additional relevant variable is risk aversion as influences the concavity of individual utility functions, and thus the expected utility gain. As the demand for PHI is expected to show a negative slope, insurance premium should show a negative effect in the insurance decision. Following Besley et al (1999) [2] the role of income is as follows: If quality of care is a normal $\operatorname{good} \frac{\partial V}{\partial y}>0$, then there is a threshold income $y^{*}$ determining the purchase of private health insurance. Therefore, we should expect a positive influence of income in the demand for PHI quality. Quality of private and NHS health care should show opposite effects. Whereas a rise in the perceived quality of NHS health care should reduce the probability of purchasing PHI, a rise in private health care quality should increase in the probability of insurance. Therefore, the quality gap between the NHS and private health care could appear as the explanatory variable 
of the PHI demand. Accordingly, in that case there is no relevant difference in the PHI demand between increasing the quality of care or decreasing the PHI quality of care. The probability of illness is expected to show an ambiguous effect. Even though individuals with a larger probability of illness are more likely to demand PHI, increases in insurance premiums as a result of a larger probability of illness show the opposite effect. Finally, a greater risk aversion will increase the expected utility of purchasing health insurance. 


\section{The empirical model}

This section explicitly describes the empirical model and a detailed description of the variables used in the analysis.

\subsection{The empirical specification}

According to the theoretical model discussed in the previous section, the empirical specification will be based in the following model.

$$
I= \begin{cases}1 \text { if } & V G=V_{1}\left(Q^{1}, y, \pi, \eta\right)-V_{0}\left(Q^{0}, y, \eta\right) \geq 0 \\ 0 \quad \text { otherwise }\end{cases}
$$

where $I$ equals one when the individual purchases PHI. We assume that the expected utility gain depends heavily on the relevant variables, allowing also for observed (X) and unobserved heterogeneity $(\varepsilon)$ to influence it. Under these assumptions equation (5) becomes:

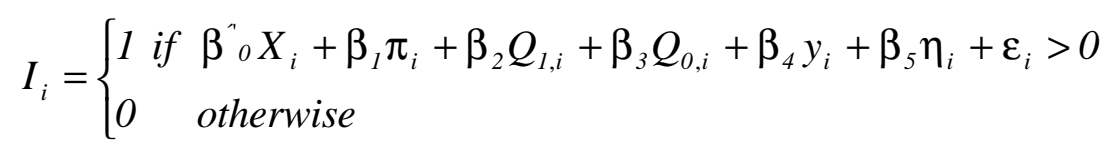

where $\varepsilon_{i}$ is assumed to be normally distributed with zero mean and unit variance, i.e we assume a probit specification. In the vector $\mathrm{X}$ we include risk aversion, variables which aim to control for a geographic effect and also the degree of health care utilisation (M). On the other hand, as we do not observe the probability of illness, we include variables which proxy them (age, self-reported health status and existence of disability) as noted before.

Additionally, given the characteristics of the data and the variables employed, the premium and the quality perception of $\mathrm{PHI}$ are not observable for those individuals not having PHI. In order to correct this sample selection problem and also the possible endogeneity of those variables, we estimate reduced form equations for these variables, including a correction 
term to control for sample selection [24] . Additionally, we use these estimated equations to make unconditional predictions for both the premium ${ }^{2}$ and the quality perception of PHI for all these individuals, to be used as instruments for the original variables in a kind of two-stage least squares procedure ${ }^{3}$ [25].

Given the form in which the private insurance premium is fixed in Spain, we include as regressors in the premium reduced form equation the following variables: age, members of the household unit covered by PHI, family income and health status proxied by the existence of disability and (self-reported) health status of the head of the household. On the other hand, in the reduced form equation for quality perception of PHI we include as regressors: age, education and (self-reported) health status of the head of the household.

\subsection{Variables}

a) Health care quality $\left(Q_{0}, Q_{1}\right)$

Quality variables tend to show a large dimensionality sometimes difficult to identify. Ideally, indicators of health care quality should rely on measures of treatment performance. Following Li and Benton (1996) we may distinguish between internal and external quality measures [26]. The latter refers to individual quality perceptions and satisfaction measures, whereas the first ones capture the adequacy of health care supplied to the specific patient. Due to the complexity of accounting for treatment performance, we didn't find any accepted internal quality indicator applicable to this study. Previous studies rely on indirect measures of internal quality [6,7]. Indirect quality measures are based on some specific dimensions of health care. Examples of these are (long -term) waiting lists or waiting time measures $[2,3,7,19]$. However, these sort of kinds of indicators are restricted to the measurement of the promptness of health care delivery as a rationing instrument. The association between the length of waiting lists and the demand for health insurance may be indicative of the stylised

\footnotetext{
${ }^{2}$ Given that we specify the premium in $\log s$ in the reduced form equation, the predicted values are obtained as $\pi=\exp \left\{\ln \pi+\frac{1}{2} \sigma^{2}\right\}$.

${ }^{3}$ This type of approach is similar to that used in the estimation of labour supply equations when trying to solve the unobservability of wages for those who do not work and its possible endogeneity.
} 
fact that improving access to the NHS reduces the demand for PHI. Moreover, internal quality indicators do not account for differences in the valuation of quality across individuals.

In this study we employ a measure of external quality of care based on consumer perceptions. It refers to the perceived quality elicited from a global individual judgement among private and NHS health care without distinguishing between different quality dimensions. We employ a specific ascending scale measure, ranging from 10 (excellent) to 1 (very bad). For comparative reasons, our purpose is to obtain a global and homogenous measure of perceived quality of care. We assume that all individuals are able to assess a value to the quality they perceive from NHS health care and private health insured individuals are able to assess a value to private health care. As hypothesised in section 3 , we expect this variable to show a significant effect in the demand equation. The higher the NHS quality perceived by the individual, the less likely she will purchase PHI. Consequently, the quality of private health care should show an opposite pattern. The higher the quality perceived from private health care the more likely the purchase of PHI.

The determinants we used to instrument health care quality are age, education and health. Accordingly, we measure the influence of age using four dummy variables (see data Appendix). A first dummy variable (Age 1) captures young age until the age people tend to have children around 30. A second dummy variable (Age 2) includes the age ranging from 30 to 44 where people tend to have children. A third dummy (Age 3) includes age from 45-64 refers to an age range where some acute diseases appear more intensively, and finally a fourth dummy variable (Age 4) captures individuals older than 64 where health utilisation tends to be more intense and chronic diseases appear more intensively. We include education by defining a set of five dummy variables (Education 1-5) according to educational success, ranging from primary studies to university studies. Finally, health status has been measured by a qualitative self-reported health status variable where 1 equals bad perceived health and 5 equals excellent perceived health. Age and health status tend to be associated with health utilisation [27], therefore we expect them to be respectively negatively and positively associated with the perception of quality. The older the individual the more likely to have some previous experience with medical treatment and thus to identify "failures" in the provision of health care. Education may be associated with medical information and knowledge [28]. Hence, 
better informed consumers should be more likely to perceive the benefits and costs of purchasing private health insurance to improve their health care choice.

\section{b) Insurance premium $(\pi)$}

Since PHI premiums extensively differ from one insurer to another, no standardised insurance premium information was available. Therefore, we measure the effects of the insurance premium as the declared insurance premium for every household member covered (see data appendix). However, we only observe insurance premia for those individuals that have purchased PHI. As noted before, we expect the premium to show a negative effect on the demand for PHI. We hypothesise that insurers will charge different premia according to those identifiable factors that influence the probability of illness and health care utilisation. Premia are expected to vary with age, health status, and existence of any disability and household size. Age is important because it is a common practice for insurance companies to charge different premiums according to age and to request information on health status and the existence of any disability. Thus, insurance premium is expected to rise with age showing a negative influence as included in the premium equation Furthermore, we include the effect of income to capture possible differences in the coverage level of PHI policies. Richer individuals may be willing to pay more for a larger coverage than poorer individuals.

\section{c) Income (y)}

As noted in previous studies and in the theoretical model, income is catalogued as an influential variable. The demand for PHI should differs across the income distribution. The higher the income the more likely individuals would purchase private health insurance. Income is measured as a net monthly income as we think individuals might show fewer difficulties in eliciting their monthly income than their annual income.

d) Probability of illness $(\eta)$ 
Given that the probability of illness is not observable, we proxy that variable using illness measures and age. Illness has been measured using two different variables. First we include a standard measure of general health status, the self reported health status (perceived health). Furthermore, the second measure indicates the existence of any disability (Disability). Both are expected to show a negative impact in the decision to purchase a PHI, as they would be associated with higher medical expenses. We assume that if health status is relatively unobservable by insurers, those expecting to be in good health have little to gain from insurance. However, available data refers to current rather than expected health status. Previous studies identify some difficulties with this interpretation [29] as far as health status may be associated with income. However, Propper (1993) [12] found no clear relationship between health status and latent demand. As noted previously, we also include age which is a variable reflecting the deterioration of health status, therefore we may expect a positive sign of the age coefficient in the demand equation. As its shown in figure 1, being in a young and healthy age category that is associated with having children is expected to display a positive influence in the demand equation.

\section{e) Other variables $(X)$}

\section{Expected medical consumption $(M)$}

In the theoretical model, expected health expenditure may determine the benefits obtained from PHI respect of consuming private health care out of pocket. An additional reason explaining the influence of expected medical consumption is that part of the value of PHI may be attributed to additional medical expenses insured will consume with PHI. We depict the influence of expected medical consumption by assuming that current consumption will approximate expected consumption. Thus, variables included were the number of visits to the general practitioner (GP visits) and outpatient visits (Specialist visits) in the last three months. A higher medical consumption of those privately insured may be understood as an evidence of moral hazard [12]. That is, as individuals show less access barriers when privately insured they tend to consume more. Particularly, this may be the case of outpatient visits, as under PHI schemes there is no need for a referral from the GP. However, this is not the case 
of GP visits as the number of visits to the NHS GP may be influenced by the need to obtain subsidized prescribed medicines [21].

\section{Attitudes towards risk}

One of the economic purposes of health insurance is to reduce financial uncertainty as a result of illness. Therefore, the higher risk aversion individual face, the more likely she will purchase health insurance. Manning and Marquis (1996) [27] directly estimated the revealed risk aversion parameter using experimental data on insurance preferences over full coverage and catastrophic limit insurance. Propper (1993) [12] measured attitudes towards risk by means of a dummy variable asking the respondent to report whether an individual would consider paying for private health insurance at the point of demand. Unlike former Spanish studies we include a variable of attitudes towards risk. To this extent we use a qualitative scale variable ranging from 1 (extremely risk averse) to 10 (risk lover).

\section{Geographical differences}

The structure of the Catalan health system show sensible differences in the availability of privately provided health care across capitals of provinces and other villages. Those living in a capital may benefit the most from purchasing PHI. Therefore, we may expect the variable Capital, (see data Appendix) to show a positive coefficient. 


\section{Results}

Table 2 presents some descriptive statistics of those variables used classified according to having purchased PHI. In particular, we observe sensible income differences between the two groups. This may be interpreted as a preliminary evidence that PHI is a normal good given that the average income is higher among the insured. Looking at household characteristics (see Table 2) we find that the privately insured tend to be highly educated, risk averse and relatively well off. Moreover, figure 1 indicates that age places a relevant role in determining PHI purchase. Perceived health and GP visits do not appear to significantly differ between the two groups. Looking at outpatient visits, we find that privately insured seem to visit specialists nearly twice as much as the uninsured.

\section{Insert table 2 here}

Estimation results are shown in table 3 . The first column shows the results from the reduced form of the insurance demand equation. The second column refers to the perceived quality equation of PHI and the third column refers to the premium equation. Finally, the estimation result of the structural equation for the PHI purchase decision as specified in equation (6) is presented in the forth column.

\section{Insert table 3 and 4 here}

A first overview of the results suggests that many of the observed effects obtained by examining raw statistics are confirmed in the demand equation. Looking at the reduced form estimates of the demand for health insurance (in the first column) we find that raises with income, age, some sources of health care utilisation and education.

The structural form (fourth column of table 3) shows the main findings. It's shown the combined influence of perceived quality of both the NHS and PHI health care in the demand 
for PHI. The coefficients are negative and positive respectively as predicted, and appear to be significant and robust. Moreover, both coefficients are very similar in absolute values. Results confirm the hypothesis that widening the gap between the public and privately financed health care increases the probability of purchasing a PHI policy. Therefore, rising the quality of NHS health care enhances a similar effect on the PHI demand as a reduction in quality of the PHI in the same magnitude. This confirms the previous theoretical intuition and fits in the structure of a conditional discrete choice model where those variables which differ not only across individuals but also across alternatives have the same coefficient, meaning that what matters in terms of the decision is the difference of values of these variables between alternatives.

The influence of the insurance premium shows a correctly signed coefficient. Table 4 shows an average absolute price elasticity estimate of 0.429 . Analysing how price elasticity differs with age, location and NHS quality perceptions we find significant differences for older individuals and those living in a provincial capital. Price elasticity rises with age until an age of 60 years old that starts reducing. People living in non-urban areas and those that perceive a high quality form the NHS care show higher price elasticities. The significance of age may be explained because quality of care starts being more valued once consumers have more experience with health care and realize they future medical expenses. Moreover, as insurers tend to exclude elderly or alternatively rise insurance premia according to age, this effect should result in lower price elasticity. The geographical effect shows that as people living in the capital, are more sensitive to small changes in benefits and costs of purchasing PHI that people living outside, as access and availability of private health care is higher in provincial capitals . As predicted, NHS quality is to increase price elasticity because those individuals that perceive a higher quality from the NHS are more sensible to differences in prices.

As predicted, net income appears to display strong, robust and significant effects. Following Besley et al (1999) [2], the individual position in the income distribution shows a strong influence in the demand for PHI. Table 4 shows that income elasticity's decrease with age, indicating that demand is sensibly correlated with the life cycle. The younger the individual the less likely is to suffer from illness and the more luxurious is PHI. Income elasticites are lower if individuals live in the provincial capital as there is a larger availability and variety of private health care providers. 
Variables that proxy health status display the correct sign, but they are not significant. A poorer health status is not associated with a higher probability of purchasing PHI. This may be interpreted as an evidence to reject the existence of adverse selection. However this result should be interpreted cautiously. On the one hand, the effect of health will be partially captured mainly by age variables. On the other hand, we have used a proxy variable for expected future health status rather that a direct measure of revealed expected health status. Regarding health care utilisation, outpatient visits appear to be significant but not GP visits. The significance of the outpatient visits can be seen as a particular case where private health insurance may improve access to health care - avoiding outpatient waiting lists - by purchasing PHI, as there is no need for GP referrals. However, this variable is sensible to the role of education as a higher health information may induce patients to decide for themselves the sort of health professional they are looking for [28]. The non significance of GP visits may be explained by two features. First, access barriers in visiting the GP are very small or even inexistent. Second, NHS GP visits are sometimes motivated by the need of obtaining a subsidised prescription. The geographical variable (capital) show a strong significant effect. In particular the variable capital is positively associated with the demand for PHI reflecting the fact that the availability of private health care is greater in the regional capital. Finally, attitudes towards risk are significant displaying a negative sign. The meaning of this result is that the more risk averse the individual is (small values in the risk attitude variable) the more likely she is to purchase a PHI policy.

Second column of table 3 shows that quality of care is associated with age and education. As far as the young individuals use less the NHS, there are less sensitive to quality variations compared to old individuals. Moreover, the more educated the individuals are, the higher the value of NHS quality. This may be explained by possible interactions with income as well as by the fact that perceived quality is the result of a higher health care knowledge and health information, typically associated with education [28].

The third column of table 4 shows that household size and age are significant predictors of the insurance premiums. Since a large household size increases the expected health care consumption the determinants of insurance premiums may have picked up this upward effect. Age, as already explained, influences the degree of health care utilisation. Thus, higher insurance premia are set to older individuals. An additional variable included is income. 
The reason is that premiums reflect differences in the PHI coverage that are supposed to be influenced by income. Since income shows a positive and significant effect this hypothesis may be confirmed.

Age shows two opposite effects. First, the older the individual is, the less likely she is to be healthy, what in turn increases the likelihood of purchasing a PHI policy (illness effect). The second effect reflects the common practice of insurers to attach higher premiums to older individuals (premium effect). Hence, the effect of age in the reduced form captures the net effect of these two variables. As estimates form table 3 show that PHI demand rises with age, this may be interpreted as an evidence of the dominance of the "illness effect" over the premium effect. The hidden dummy variable is Age 4, referring to those individuals older than 60. This result is consistent with other Spanish studies [15].

From the reduced form we find that those variables that appear to be significant in the structural equation remain significant and show similar effects. Demand for PHI is positively associated with education. This may be the result of the latent variables that explain the quality of care perceptions. A positive parameter was observed as well by other previous studies based on larger samples $[\mathbf{1 5 , 1 6 , 1 7 ]}$. However, notice that education shows a significant effect in the quality perception and as expected is negatively associated with the purchase of PHI. Those individuals with lower education attainment are less able to perceive the quality gap between public and private health insurance. Household size has a negative sign but does not appear to show any significant effects when included in the reduced form. 


\section{Discussion}

In this paper we have investigated the role of quality of care in determining the demand for PHI. Former studies investigate equilibrium systems with PHI showing two stylised facts. First, the opting out of the public sector is the result of a lack of quality and flexibility of the publicly financed care [7,8,9]. Second, the effect of the expansion of the NHS care may crowd out the private sector [30]. However this would depend on the capacity of the private sector to adjust their quality to maintain PHI demand. We find that if the NHS increases perceived quality in a $10 \%$ this would be equivalent to a reduction of a $10 \%$ in the PHI quality. This study integrates this two issues from an individually based perspective. Another novelty that this paper introduces is the estimation of price elasticities for Spanish data. The relevance of price elasticity estimates relies on the information that includes on the impact of cost sharing policies. Demand elasticities show that PHI appears to be quite insensitive to premium variations. The interpretation following Manning and Marquis (1996) [27] is that the larger the price elasticity ceteris paribus, the greater the welfare loss resulting from more generous health insurance. Consistently with previous evidence quality of care is a normal good and income elasticity are higher than one, suggesting that PHI is a luxury good, which is consistent as well with some previous studies based on aggregate demand analysis [17].

Results suggest that PHI demand is very sensitive to health care quality perceptions. The Catalan NHS strongly suffers from quality limitations, steaming from the long waiting lists in some procedures (i.e elective surgery) and other access limitations. This is consistent with recent literature on the impact of waiting lists and waiting time in the demand elective surgery in Britian [1,31,32]. In particular, Gravelle et al (2001) [32] show that performance measures have a large influence in patient's demand for health care. Current health policy debate pretends to encounter optimal instruments to promote quality and efficiency using private substitutes of publicly financed goods. A previous tax relief on PHI purchases has been recently removed in Spain from 1999. The low price elasticity estimated here confirm that subsidising health care consumption would have a small effect on demand whereas improving NHS quality may effectively show an impact on the demand for PHI. 
Limitations of this study are the following. First, the database employed is small even though data was representative and no missing data problems were found. In Catalonia, such as in those countries where the purchase of PHI is linked to social and familiar tradition, there may be alternative explanations to the ones that are provide by standard insurance theory. Trust with physicians, information asymmetries and information costs may refrain individuals to switch from one insurer to another. This may require the use of panel data analysis in order to capture time effects as well as individual effects [33]. Propper (2000) [34] shows examining the British Household Panel Survey that use of private (NHS) health care is explained by past used of private (NHS) health care, what may suggests a that other determinants as PHI purchasing tradition may be strongly relevant even when estimating the determinants of PHI. Other studies employing proxies for quality of care variables have already shown a negative impact on the demand for health insurance. In particular, Jofre (1998) [19] argued that assuming the quality of private health care as fixed, the effects of increasing the quality of the NHS are to trigger the substitution between the public and private health care. However, dismissing the effects that PHI quality may have on the demand for PHI is a strong assumption. In this study, quality of private health care was not assumed to be fixed as information on PHI quality was available. As private health care may show a larger flexibility to new circumstances compared to the NHS, it seems necessary to include the influence of PHI quality perceptions to completely account for the determinants of PHI demand. Our results show that NHS and private health care if allowed to interact, show an equivalent and opposite effect in the demand for health insurance. 
Table 1.

Population holding private insurance policies in Catalunya

\begin{tabular}{cc}
\hline Year & Share \\
\hline 1994 & 0.228 \\
1995 & 0.222 \\
1996 & 0.230 \\
1997 & 0.230 \\
1998 & 0.229 \\
\hline
\end{tabular}

Source: Anuari Estadísitic de Catalunya, 1999. 
Table 2.

Characteristics of privately (un) insured

(Descriptive statistics)

\begin{tabular}{|c|c|c|c|c|}
\hline & \multicolumn{2}{|l|}{ Insured } & \multicolumn{2}{|c|}{ Uninsured } \\
\hline & Mean & Std. Dev & Mean & Std. Dev \\
\hline Age & 53.7 & 16.92 & 53.8 & 17.1 \\
\hline $\begin{array}{l}\text { Net Income } \\
\text { (thousand PTAs) }\end{array}$ & 225,2 & 107,8 & 185,6 & 87,8 \\
\hline Household size & 2.68 & 1.13 & 2.68 & 1.25 \\
\hline Education 1 & 0.41 & 0.49 & 0.64 & 0.47 \\
\hline Education 2 & 0.14 & 0.35 & 0.12 & 0.32 \\
\hline Education 3 & 0.09 & 0.29 & 0.07 & 0.26 \\
\hline Education 4 & 0.68 & 0.25 & 0.03 & 0.19 \\
\hline Education 5 & 0.27 & 0.44 & 0.11 & 0.32 \\
\hline Disability & 0.13 & 0.34 & 0.18 & 0.38 \\
\hline Risk Attitudes & 2.72 & 1.72 & 2.94 & 1.67 \\
\hline Capital & 0.59 & 0.49 & 0.33 & 0.47 \\
\hline Specialist visits & 0.82 & 2.61 & 0.47 & 1.3 \\
\hline GP visits & 0.42 & 0.88 & 0.60 & 1.18 \\
\hline Perceived Health & 3.64 & 0.96 & 3.44 & 1.10 \\
\hline NHS care (quality) & 5.35 & 3.25 & 7.07 & 2.54 \\
\hline $\mathrm{N}$ & 87 & & 313 & \\
\hline
\end{tabular}


Table 3.

Maximum Likelihood results.

\begin{tabular}{|c|c|c|c|c|}
\hline Variable & Insurance $(*)$ & PHI Quality & $\begin{array}{l}\text { Premium } \\
(\log )\end{array}$ & Insurance \\
\hline \multirow[t]{2}{*}{ Net Income $(* * *)$} & 3.073 & & 2.091 & 4.842 \\
\hline & $(2.871)$ & & $(3.423)$ & (3.893) \\
\hline \multirow[t]{2}{*}{ Household size } & -0.097 & & 0.329 & \\
\hline & $(-1.269)$ & & $(5.829)$ & \\
\hline \multirow[t]{2}{*}{ Education 1} & -0.845 & 1.377 & & \\
\hline & $(-3.509)$ & (2.323) & & \\
\hline \multirow[t]{2}{*}{ Education 2} & -0.26135 & 1.207 & & \\
\hline & $(-0.937)$ & (1.727) & & \\
\hline \multirow[t]{2}{*}{ Education 3} & -0.177 & 0.974 & & \\
\hline & $(-0.544)$ & (1.124) & & \\
\hline \multirow[t]{2}{*}{ Education 4} & -0.542 & 1.09 & & \\
\hline & $(-1.323)$ & $(1.166)$ & & \\
\hline \multirow[t]{2}{*}{ Disability } & -0.287 & -0.549 & 0.159 & -0.175 \\
\hline & $(-1.157)$ & $(-0.732)$ & $(0.834)$ & $(-0.715)$ \\
\hline \multirow[t]{2}{*}{ Risk attitudes } & -0.087 & & & -0.087 \\
\hline & $(-1.774)$ & & & $(-1.802)$ \\
\hline \multirow[t]{2}{*}{ Capital } & 0.567 & & & 0.676 \\
\hline & (3.539) & & & (4.331) \\
\hline \multirow[t]{2}{*}{ GP visits } & 0.024 & & & 0.011 \\
\hline & $(0.311)$ & & & $(0.144)$ \\
\hline \multirow[t]{2}{*}{ Specialists visits } & 0.125 & & & 0.122 \\
\hline & $(2.456)$ & & & $(2.311)$ \\
\hline \multirow[t]{2}{*}{ NHS valuation } & -0.132 & & & -0.108 \\
\hline & $(-4.647)$ & & & $(-3.866)$ \\
\hline \multirow[t]{2}{*}{ Age1 } & -1.138 & 1.621 & -0.376 & -0.909 \\
\hline & $(-3.425)$ & (1.732) & $(-1.734)$ & $(-2.973)$ \\
\hline \multirow[t]{2}{*}{ Age2 } & -0.592 & 0.688 & -0.39348 & -0.565 \\
\hline & $(-2.298)$ & (1.077) & $(-2.372)$ & $(-2.344)$ \\
\hline \multirow[t]{2}{*}{ Age 3} & -0.392 & 0.112 & -0.1467 & -0.418 \\
\hline & $(-1.811)$ & $(0.196)$ & $(-0.975)$ & $(-1.990)$ \\
\hline \multirow[t]{2}{*}{ Bad Health } & -0.283 & 1.726 & 0.077 & -0.456 \\
\hline & $(-0.711)$ & (1.263) & $(0.22)$ & $(-1.121)$ \\
\hline \multirow[t]{2}{*}{ PHI Qualityf (**) } & & & & 0.100 \\
\hline & & & & (1.707) \\
\hline \multirow[t]{2}{*}{ Premiumf $(* *)$} & & & & -2.221 \\
\hline & & & & $(-1.659)$ \\
\hline \multirow[t]{2}{*}{ Intercept } & 0.609 & 7.361 & 8.138 & -1.321 \\
\hline & (1.427) & (12.316) & (8.055) & $(-2.027)$ \\
\hline \multirow[t]{2}{*}{ Lambda } & & -0.52 & 0.091 & \\
\hline & & (0.603) & $(0.249)$ & \\
\hline$\rho$ & & -0.416 & -0.121 & \\
\hline $\begin{array}{l}\text { (Pseudo) } R^{2} \\
\text { square }\end{array}$ & 0.188 & 0.19 & 0.46 & 0.171 \\
\hline $\mathrm{N}$ & 400 & 87 & 87 & 400 \\
\hline
\end{tabular}

(*) Reduced form of the model.

(**) Refers to the linear prediction, measured in millions of PTA's

$(* * *)$ Measured in millions of PTA's. 
Table 4. Elasticity estimates for PHI

\begin{tabular}{lll}
\hline & $\left|E_{p}\right|$ & $E_{y}$ \\
\hline All sample & 0.429 & 1.962 \\
Age 1 (less than 30) & 0.438 & 2.751 \\
Age 2 (30-44) & 0.439 & 2.403 \\
Age 3 (45-64) & 0.497 & 2.094 \\
Age 4 (more than 64) & 0.328 & 1.263 \\
Capital & 0.325 & 1.464 \\
High NHS quality & 0.453 & 2.085 \\
(individual perception) & & \\
\hline
\end{tabular}


Figure 1.

Private medical insurance by age groups

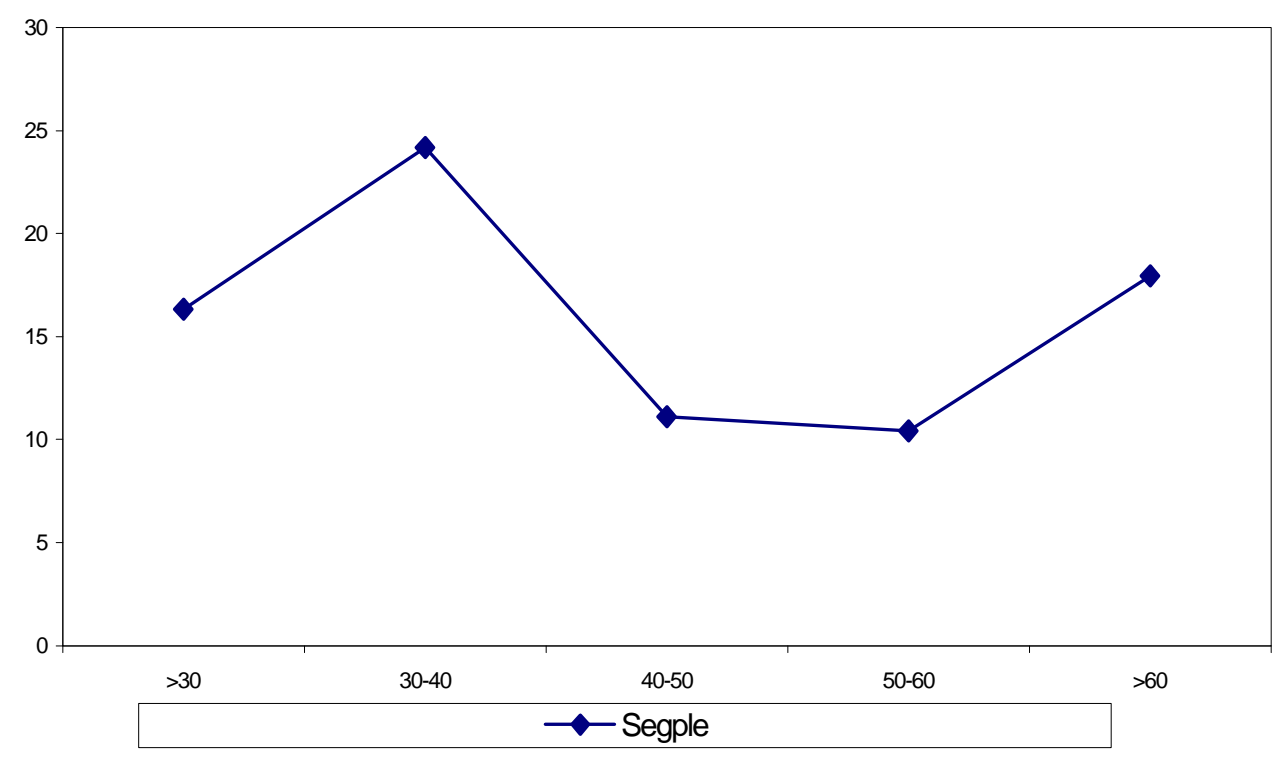




\section{References}

1. Besley, T ; Hall, J and Preston, I (1996). Private health insurance and the state of the NHS. IFS commentary, No 52, London. Institute of Fiscal Studies.

2. Besley, T ; Hall, J and Preston, I (1999). The demand for private health insurance: do waiting lists matter? Journal of Public Economics, 72:155-181.

3. Besley, T ; Hall, J and Preston, I (1998). Private and public health insurance in the UK. European Economic Review, 42:491-97.

4. Besley, T and Gouveia, M (1994). Alternative systems to health care provision. Economic Policy 19: 199-258.

5. Nyman, J (1999). The value of health insurance: the access motive. Journal of Health Economics, 18:141-152.

6. Lindslay, M.C and Feigenbaum, B (1984). Rationing by waiting lists. American Economic Review, 74, 404-417.

7. Iversen, T (1997). The effect of a private sector on the waiting time in a national health service. Journal of Health Economics, 16: 381-396.

8. Besley, T and Coate, $\mathrm{S}$ (1991). Public provision of private goods and the redistribution of income. American Economic Review, 81:979-84.

9. Epple, D and Romano, R (1996). Public provision of private goods. Journal of Political Economy, 104:57-84.

10. Gouveia, M (1996). The public and private sector and health care. International Tax and Public Finance, 3(3): 329-50.

11. Hall, J and Preston, I (1998). Public and private choice in UK health insurance. WP 98-4 Institute of Fiscal Studies.

12. Ireland, J (1990). The mix of social security and private provision of goods and services. Journal of Public Economics 43, 201-219.

13. Propper, C (1993). Constrained choice sets in the UK demand for private medical insurance. Journal of Public Economics 51, 287-307.

14. Costa, J (1999). Assegurament individual, conducta i elecció col-lectiva : una aplicació a la política sanitaria. PhD Thesis, Universitat de Barcelona.

15. Calnan, M ; Cant, M and Gabe, J (1993). Going private; why people pay for their health. Buckingham: Open University.

16. Gonzalez, Y (1995). La demanda de seguros sanitarios. Revista de Economia Aplicada, 8: $111-142$.

17. Murillo C, Calonge, S and González, Y (1996). La financiacion de los servicios sanitarios en Espana. FEDEA, Documento de Trabajo.

18. Szabó, T (1997) La demanda de seguros privados y el uso de servicios sanitarios en España. Tesina CEMFI 9706.

19. Jofre-Bonet, M (1998). Health care: interaction between public systems and private sector. PhD Thesis, Universitat Pompeu Fabra.

20. Palenzuela, D.R (1997). Provision of private health insurance under public insurance captivity. Documento de Trabajo FEDEA, 97-17.

21. Vera-Hernández, A.M (1999). Duplicate coverage and demand for health care. The case of Catalonia. Health Economics, 8:579-598.

22. López, G (1999). Health Care and Cost Containment in Spain. In Mossialos, E and Le Grand, J (eds) Health Care and cost Containment in the European Union. Ashgate, London. 
23. Johanesson, M Johansson, P-O and Söderqvist, P (1998). Time spent on waiting lists for medical care : an insurance approach. Journal of Health Economics, 17:627-644.

24. Heckman, J.J (1976). The Common Structure of Statistical Models of Truncation. Sample Selection and Limited Dependent Variables and Simple Estimation for Such Models. Annals of Economic and Social Measurement 5:475-492.

25. Nelson, F.D and Olson, L (1978). Specification and Estimation of a Simultaneous Equation Model with Limited Dependent Variables, International Economic Review, 19:695-710.

26. Li, LX and Benton, W.C (1996). Performance measurement criteria in health care organisations: review and future research directions. European Journal of Operational Research, 93: 449-468.

27. Manning, W.C and Marquis, M.S (1996). Health insurance: the trade off between risk pooling and moral hazard. Journal of Health Economics 15:609-639.

28. Kenkel, D (1990). Consumer health information and the demand for medical care. The Review of Economics and Statistics, 30: 587-95.

29. van de Ven, W and van Praag, B (1981).The demand for deductibles in private health insurance. A probit model with sample selection. Journal of Econometrics, 17, 229-252.

30. Cutler, D.M and Gruber, J (1995). Does public insurance crowd out private insurance? NBER, WP 5082.

31. Martin, S and Smith, P.C (1999). Rationing by waiting lists: an empirical investigation. Journal of Public Economics, 41:141-164.

32. Gravelle, H Smith, P.C and Xavier, A (2000). Waiting lists and waiting times : a model of the market for elective surgery. Journal of Health Economics (forthcoming).

33. Propper (1999). Public provision and private demand : the case of private health care in the UK. Department of Economics, University of Bristol.

34. Propper (2000)The demand for private health care in the UK. Journal of Health Economics, 19 (2000): 855-876. 
DATA APENDIX

Summary of variables employed

\begin{tabular}{|c|c|c|c|}
\hline Variable & Type & Definition & $\begin{array}{l}\text { Mean } \\
\text { (Std. Dev) }\end{array}$ \\
\hline $\begin{array}{ll}\text { Private } & \text { Health } \\
\text { Insurance } & \end{array}$ & Dummy & Respondent has purchased a PHI policy & $\begin{array}{l}.23 \\
(.44)\end{array}$ \\
\hline NHS care quality & Qualitative & $\begin{array}{l}\text { Respondent assessment from } 10=\text { excellent to } \\
1=\text { very bad }\end{array}$ & $\begin{array}{l}6.71 \\
(2.79)\end{array}$ \\
\hline PHI health care quality & Qualitative & $\begin{array}{l}\text { Respondent assessment from } 10=\text { excellent to } \\
1=\text { very bad }\end{array}$ & $\begin{array}{l}8.64 \\
(2.02)\end{array}$ \\
\hline $\begin{array}{l}\text { Premium (head of the } \\
\text { family) }\end{array}$ & Numerical & Premium paid & $\begin{array}{l}7117 \\
(3216)\end{array}$ \\
\hline Premium (Children) & Numerical & Premium paid & $\begin{array}{l}6285 \\
(1726)\end{array}$ \\
\hline Premium (Other) & Numerical & Premium paid & $\begin{array}{l}5567 \\
(2082)\end{array}$ \\
\hline Age & Numerical & Respondent Age & $\begin{array}{l}53.9 \\
(17.0)\end{array}$ \\
\hline Age1 & Dummy & Less than 30 & $\begin{array}{l}0.12 \\
(0.32)\end{array}$ \\
\hline Age 2 & Dummy & Between 30 and 44 & $\begin{array}{l}0.25 \\
(0.43)\end{array}$ \\
\hline Age 3 & Dummy & Between 45 and 59 & $\begin{array}{l}0.27 \\
(0.44)\end{array}$ \\
\hline Age 4 & Dummy & More than 60 & $\begin{array}{l}0.47 \\
(0.47)\end{array}$ \\
\hline $\begin{array}{l}\text { Net Income } \\
\text { (thousand PTAs) }\end{array}$ & Numerical & $\begin{array}{l}\text { Individually declared monthly average } \\
\text { income after taxes and insurance premium } \\
\text { payments }\end{array}$ & $\begin{array}{l}190.3 \\
(94.0)\end{array}$ \\
\hline Household size & Numerical & Number of members of the household & $\begin{array}{l}2.67 \\
(1.22)\end{array}$ \\
\hline Education 1 & Dummy & Respondent has a primary school degree & $\begin{array}{l}0.59 \\
(0.49)\end{array}$ \\
\hline Education 2 & Dummy & Respondent has a secondary school degree & $\begin{array}{l}0.13 \\
(0.33)\end{array}$ \\
\hline Education 3 & Dummy & $\begin{array}{l}\text { Respondent has baccalaureate degree (pre- } \\
\text { university studies) }\end{array}$ & $\begin{array}{l}0.08 \\
(0.27)\end{array}$ \\
\hline Education 4 & Dummy & Respondent has a medium university degree & $\begin{array}{l}0.04 \\
(0.20)\end{array}$ \\
\hline Education 5 & Dummy & Respondent has a superior university degree & $\begin{array}{l}0.15 \\
(0.35)\end{array}$ \\
\hline Disability & Dummy & Respondent has a chronic condition & $\begin{array}{l}0.17 \\
(0.38)\end{array}$ \\
\hline Risk Attitudes & Qualitative & $\begin{array}{l}\text { Respondent risk attitudes ranging from is risk } \\
\text { aversion }=1 \text { to risk seeking }=10\end{array}$ & $\begin{array}{l}2.89 \\
(1.68)\end{array}$ \\
\hline Capital & Dummy & $\begin{array}{l}\text { Respondent residence is in the capital of a } \\
\text { province }\end{array}$ & $\begin{array}{l}0.40 \\
(0.49)\end{array}$ \\
\hline Specialist visits & Numerical & $\begin{array}{l}\text { Number of specialist visits in the last } 3 \\
\text { months }\end{array}$ & $\begin{array}{l}0.55 \\
(1.67)\end{array}$ \\
\hline GP visits & Numerical & Number of GP visits in the last 3 months & $\begin{array}{l}0.56 \\
(1.12)\end{array}$ \\
\hline Perceived Health & Qualitative & $\begin{array}{l}\text { Respondent assessment of its health status } \\
\text { from } B a d=1 \text { for excellent }=5\end{array}$ & $\begin{array}{l}3.48 \\
(1.05)\end{array}$ \\
\hline
\end{tabular}


